\title{
Viscosity Index for Oil Used as Biodegradable Lubricant
}

\author{
loana Stanciu* \\ University of Bucharest, Faculty of Chemistry, Department of Physical Chemistry, 4-12 \\ Elisabeta Blvd, Bucharest, Romania
}

Article Type: Article

Article Citation: Ioana Stanciu. Viscosity index for oil used as biodegradable lubricant. Indian Journal of Science and Technology. 2020; 13(03), 352-359. D0l: 10.17485/ ijst/2020/v013i03/147759

Received date: March 13, 2019

Accepted date: April 2, 2019

*Author for correspondence: loana Stanciu \istanciu75@ yahoo.com 9 University of Bucharest, Faculty of Chemistry, Department of Physical Chemistry, 4-12 Elisabeta Blvd, Bucharest, Romania

\section{Abstract}

Objectives: To study the viscosity index for oil used as biodegradable lubricant using tree methods. Methods: Viscosity index for oil used as biodegradable lubricant (coconut oil, soybean oil, corn oil, rapeseed oil) was determined using a set of Schott Ubbelohde-type viscometers selected according to the values of their constants, so that the margins of the uncertainty, inherent in the Hagebach-Couette correction, does not exceed the error allowed for the measurements. The measurements were carried out at $40 \pm 0.1$ and $100 \pm 0.1{ }^{\circ} \mathrm{C}$, according to the recommendation of ASTM D2270. Findings: The viscosity index of soybean oil is the highest and the viscosity index of rapeseed oil is the lowest. The viscosity index determined with the calculator for coconut oil is one unit higher than that obtained by the formula (1). The viscosity index of corn oil determined with relation (1) is 151 , and the one determined by computer is 25 units higher. The viscosity index of rapeseed determined with relation (1) is 143 , and the one determined with the computer program is 23 units higher. The viscosity index determined for soybean oil determined using the program has a negative value. The viscosity oils used as biodegradable lubricant were determined using tree methods: ASTM D 2270 and method graphically using ASTM D 341. Viscosity index calculation was performed with a computer program using kinematic viscosity at $40{ }^{\circ} \mathrm{C}$ and $100{ }^{\circ} \mathrm{C}$. The viscosity-temperature coefficient for oils used as biodegradable lubricant can vary by a factor of 10 depending on the temperature. The viscosity of oil oils used as biodegradable lubricant is dependent upon temperature. Viscosity decreases as temperature increases because the molecules vibrate more, and interact less. Application: The three methods for determining the viscosity index can be applied both to vegetable oils used as biodegradable lubricants and to oils of SAE class. The term biodegradable lubricant includes a wide range of lubricants, such as: vegetable oils; hydrogenated vegetable oils; vegetable oils with high oleic acid content; synthetic esters produced from vegetable oils.

Keywords: Viscosity Index, Viscosity-Temperature Coefficient. 


\section{Introduction}

The main characteristics of environmentally friendly lubricants, called biodegradable lubricants are as follows: they conserve energy; longer operating time: less waste; low consumption: less throwing; they are recyclable; they are biodegradable; have low ecotoxicity; have low pollution risk for water, soil, and air.

The term biodegradable lubricant includes a wide range of lubricants, such as: vegetable oils; hydrogenated vegetable oils; vegetable oils with high oleic acid content; synthetic esters produced from vegetable oils.

Advantages and disadvantages of biodegradable lubricants: lower air, water, and soil pollution; minimal risks to health and safety; easier destruction due to their biodegradability.

More specifically, the advantages of biodegradable lubricants compared to lubricants from mineral oils are as follows: good lubrication characteristics; good corrosion inhibition properties; low volatility, leading to low emissions; very low aquatic toxicity; intrinsic biodegradability; wide availability; manufacture from renewable resources [1]

VI of the biodegradable lubricants is calculated from the kinematic viscosities at 40 ${ }^{\circ} \mathrm{C}$ of the three oils, the reference and the one whose index must be determined, using according to ASTM D 2270-93 [1] - the relation:

$$
V I=\frac{L-U}{L-H} \times 100
$$

where in $U$ is the viscosity of the oil, $L$ - that of the oil with VI 0 , and $\mathrm{H}$ - of the oil with VI 100. The relation is used to determine the viscosity indices of the oils with values less than or equal to 100, for which the value of $U$ is between $L$ and $H$.

For oils with a value $U$ lower than $H$, a situation encountered in the case of oils with VI greater than 100, a parameter $N$, calculated from $H$ and the $Y$ value of the kinematic viscosity of the oil given at $100{ }^{\circ} \mathrm{C}$, is defined and VI is given by the equation:

$$
V I=100+140 \times[(\operatorname{antilog} N)-1]
$$

where $N=(\log H-\log U) / \log Y$.

The $Y, L$, and $H$ values are tabulated in ASTM D 2270 [1] for $Y$ between 2.0 and 70.0 cSt.

Although the viscosity index describes the physical behavior of oil, it does not fall into the category of physical properties [2]. If used to indicate the type of hydrocarbons, solvent strength, compatibility with elastomers, etc. or for the selection of additives for VI improvement, it may give erroneous results.

The most convenient way to determine kinematic viscosity at temperatures other than those indicated or to determine viscosities at 40 and $100{ }^{\circ} \mathrm{C}$ from viscosities at other temperatures is the graph, using ASTM D 341 diagrams [3]. The determination is reduced to finding the viscosity at those two standard temperatures from viscosity to one temperature and VI.

There are also programs for calculating the viscosity index and other lubricant properties. 
The calculation of the viscosity index was also performed with a calculation program developed by INCERP S.A., created in a basic visual called VI. Such programs can also be found on the Internet, such as Surveyor Oil Calculator for Palm Computers Version 2.0 developed by Saylbot, Moscow, in 2002, using OrbForm version 1.2, which can be found on the website http://www.saybolt.ru/ OilCalc / Palm [2] and calculating viscosity indices based on ASTM 2270 standard.

The scale of viscosity indices established by SAE, according to ASTM 2270-93 elaborated for calculating viscosity indices of petroleum products such as lubricants and materials related to them [3-5], requires the knowledge of the kinematic viscosities of the oils at two temperatures.

The values of the viscosity indices obtained for the biodegradable lubricants (corn oil, sunflower oil, soybean oil, olive oil) using the relation (1) and the VI program developed by INCERP are presented in Table 1, together with the experimental values obtained for the kinematic viscosities at temperatures of 40 and $97^{\circ} \mathrm{C}$ and the viscosity-temperature coefficients calculated with equation (3) [7].

The viscosity indices were also determined using the ASTM D 341 diagram, shown in Figures 1-4.

It was built as follows. The kinematic viscosities for the 40 and $100{ }^{\circ} \mathrm{C}$ temperatures (calculated with the SHELL diagram from the viscosities at two other temperatures) were represented in the ASTM digram for the four oils. Those points were joined by lines for each component separately. The smaller the slope of the line, the higher the viscosity index.

For coconut oil, the value 165 was thus obtained for the viscosity index, which is identical to that obtained using equation (1) and very close to that obtained with the VI program.

Similarly, the other viscosity indices were determined.

The kinematic viscosities could not be determined at temperatures of $40 \pm 0.1$ and $97 \pm$ $0.1^{\circ} \mathrm{C}$ for all oils, as required by ASTM D2270 [1]. Therefore, to determine the kinematic viscosity at $40^{\circ} \mathrm{C}$ and $97^{\circ} \mathrm{C}$ a helper SHELL diagram was used.

The viscosity index of the coconut oil determined with relation (1) is 165 and the one determined with the respective progranus is with a larger unit. Not the same thing happens with the soybean oil that has the viscosity index 170 and with the program we get a negative value.

TABLE 1. Values of kinematic viscosities at 40 and $100{ }^{\circ} \mathrm{C}$, viscosity index and viscositytemperature coefficient for oils

\begin{tabular}{|c|c|c|c|c|c|c|}
\hline \multirow[t]{2}{*}{ Oil } & \multirow{2}{*}{$\begin{array}{l}\text { Density } \\
\left(\mathrm{g} / \mathrm{cm}^{3}\right)\end{array}$} & \multicolumn{2}{|c|}{$\begin{array}{c}\text { Kinematic } \\
\text { viscosity }\left(\mathrm{mm}^{2} / \mathrm{s}\right)\end{array}$} & \multirow{2}{*}{$\begin{array}{l}\text { Viscosity index } \\
\text { relationship } \\
\text { (1) }\end{array}$} & \multirow{2}{*}{$\begin{array}{c}\text { Viscosity } \\
\text { index pro- } \\
\text { gram VI }\end{array}$} & \multirow{2}{*}{$\begin{array}{l}\text { Viscosity- } \\
\text { temperature } \\
\text { coefficient }\end{array}$} \\
\hline & & $40^{\circ} \mathrm{C}$ & $100^{\circ} \mathrm{C}$ & & & \\
\hline Coconut & 0.9260 & 27.6 & 5.9 & 165 & 166 & 0.7862 \\
\hline Soybean & 0.9193 & 144.72 & 5.04 & 170 & -861 & 0.9651 \\
\hline Corn & 0.9188 & 30.8 & 6.57 & 151 & 176 & 0.7867 \\
\hline Rapeseed & 0.9073 & 44.9 & 8.41 & 143 & 166 & 0.8127 \\
\hline
\end{tabular}




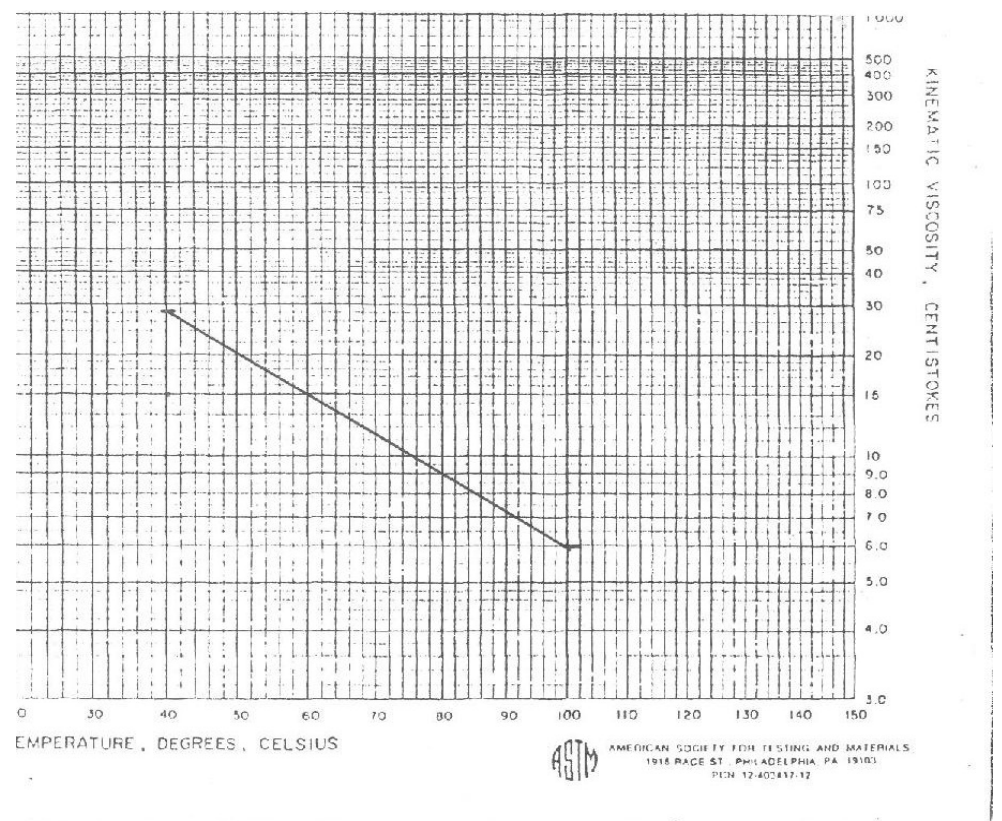

FIGURE 1. Diagram ASTM D 341 for the determination of the VI viscosity index of coconut oil.

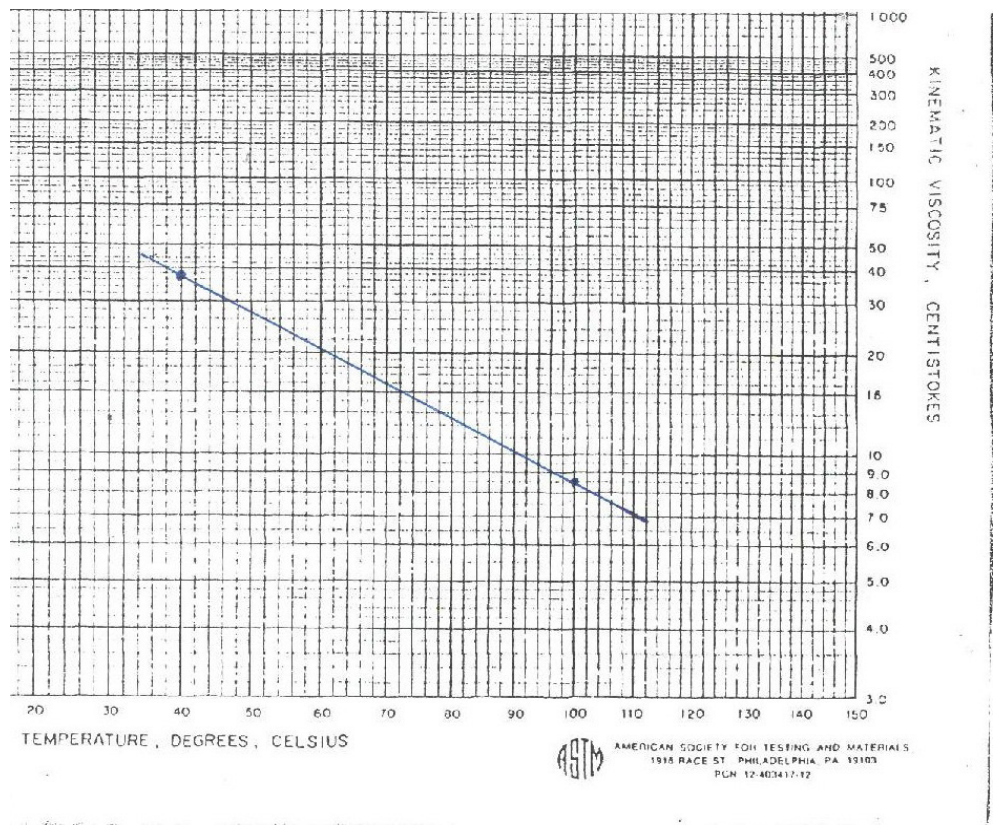

FIGURE 2. Diagram ASTM D 341 for the determination of the VI viscosity index of rapeseed oil. 


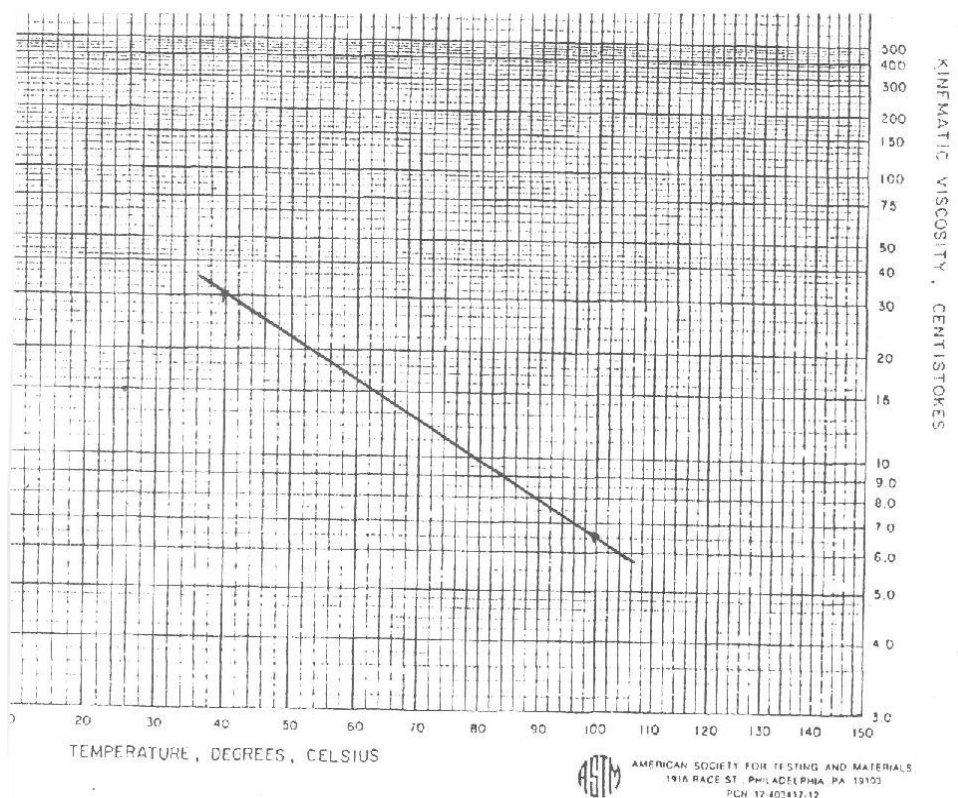

FIGURE 3. Diagram ASTM D 341 for the determination of the VI viscosity index of corn oil.

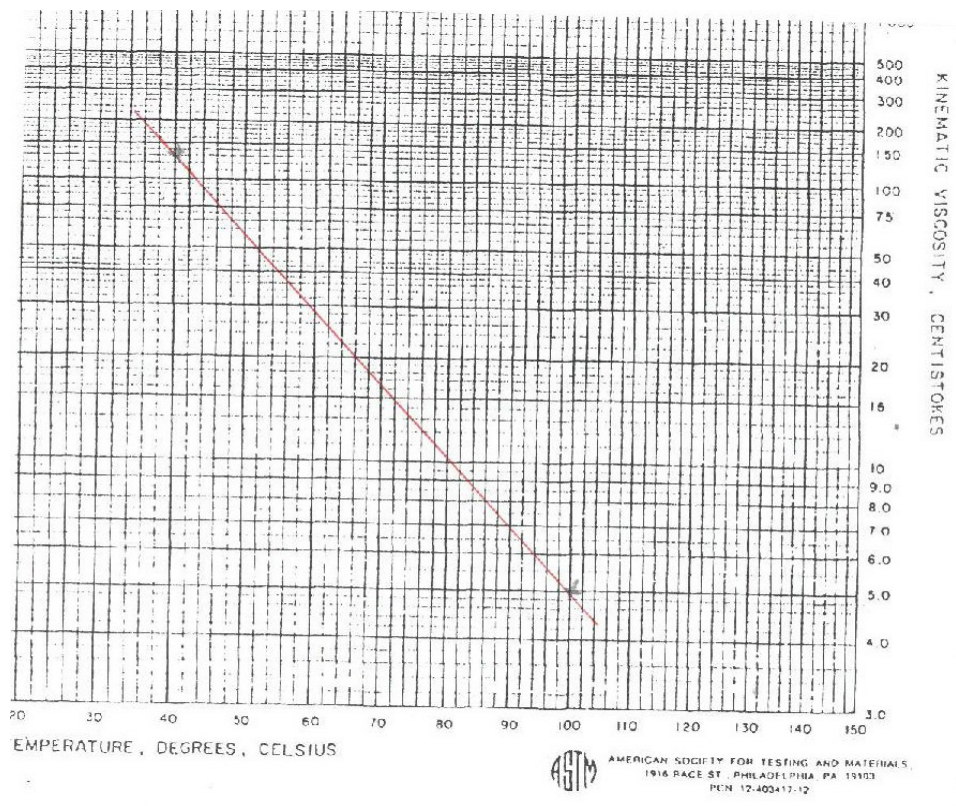

FIGURE 4. Diagram ASTM D 341 for the determination of the VI viscosity index of soybean oil. 
Another indication of the change in kinematics viscosity with temperature, which is less arbitrary than the viscosity index, is the viscosity-temperature coefficient, VTC, defined by the relationship [8-12]:

$$
V T C=(A-B) / A
$$

where $A$ is the viscosity (cSt) at $40{ }^{\circ} \mathrm{C}$ and $B$ - viscosity at $100{ }^{\circ} \mathrm{C}$. The calculated values of VTC are also given in Table 1 .

From the table, it can be seen that the values of the viscosity-temperature coefficients are lower as the viscosity indices are higher. Thus, the highest value of the viscositytemperature coefficient was obtained for soybean oil and the lowest for coconut oil.

The objective of the present study is the determination of viscosity index for oil used as biodegradable lubricant.

\section{Material and Methods}

Viscosity index for oil used as biodegradable lubricant (coconut oil, soybean oil, corn oil, rapessed oil) was determined using a set of Schott Ubbelohde-type viscometers selected according to the values of their constants, so that the margins of the uncertainty, inherent in the Hagebach-Couette correction, does not exceed the error allowed for the measurements. The measurements were carried out at $40 \pm 0.1$ and $100 \pm 0.1{ }^{\circ} \mathrm{C}$, according to the recommendation of ASTM D2270 [5-6].

\section{Results and Discussion}

Viscosity is a measure of an oil thickness and ability to flow at certain temperatures, while viscosity index is a lubricating oil quality indicator, an arbitrary measure for the change of its kinematic viscosity with temperature and provides an insight into the oil's ability to perform at high and low temperatures [7-12].

The value obtained for the viscosity index of oils coconut, oil soybean, oil corn, and oil rapessed in Table 1, together with their kinematics viscosities at 40 and $100{ }^{\circ} \mathrm{C}$ and viscosity-temperature coefficient.

Another indication of the change in kinematics viscosity with temperature, which is less arbitrary than the viscosity index, is the viscosity-temperature coefficient, VTC, defined by the relationship [13-15]:

$$
V T C=(A-B) / A
$$

where $A$ is the viscosity (cSt) at $40^{\circ} \mathrm{C}$ and $B$ - viscosity at $100^{\circ} \mathrm{C}$. The calculated values of VTC are also given in Table 1. 


\section{Conclusions}

The viscosity index of soybean oil is the highest and the viscosity index of rapeseed oil is the lowest. The viscosity index determined with the calculator for coconut oil is one unit higher than that obtained by the formula (1). The viscosity index of corn oil determined with relation (1) is 151, and the one determined by computer is 25 units higher. The viscosity oils used as biodegradable lubricant were determined using tree methods: ASTM D 2270 and method graphically using ASTM D 341. Viscosity index calculation was performed with a computer program using kinematic viscosity at $40{ }^{\circ} \mathrm{C}$ and $100{ }^{\circ} \mathrm{C}$.

The viscosity-temperature coefficient for oils used as biodegradable lubricant can vary by a factor of 10 depending on the temperature.

The viscosity of oil oils used as biodegradable lubricant is dependent upon temperature. Viscosity decreases as temperature increases because the molecules vibrate more, and interact less.

\section{References}

1. Martin Hernandez C, Benet S, Obert L. Determination of proteins in refined and nonrefined oils. Journal of Agriculture Food Chemistry. 2008; 56(12), 4348-4451.

2. Hayati IN, Che Man YB, Tan CP, Aini IN. Stability and rheology of concentrated O/W emulsions based on soybean oil/palm kernel olein blends. Food Research International. 2007; 40(8), 1051-1061.

3. Gylling H, Rapeseed oil does not cause allergic reactions. Journal of Allergy. 2006; 61(7), 895-896.

4. Liston TV, Engine Oil additives-what they are and how they function. Lubrication Engineering. 1992; 48(5), 389-397.

5. Alpaslan M, Hayta M. Rheological and sensory properties of pekmez (grape molasses)/tahin (sesame paste) blends. Journal of Food Engineering. 2002; 54(1), 89-93.

6. Fasina OO, Hallman H, Craig-Schmidt M, Clements C. Predicting temperature dependence viscosity of vegetable oils from fatty acid composition. Journal of the American Oil Chemists' Society. 2006; 83(10), 899-903.

7. Stanciu I, Leca M. Viscosity improvers for multi-grade oils. Buletin UPG - Seria Tehnică. 2007; 65-70.

8. Devlin MT, Senn J, Lai Turner T, Milner J. Reduction in axle oil operating temperatures by fluids with optimized torque transfer efficiencies. Lubrication Science. 2005; 18, 7-23.

9. Akhtar N, Adnan Q, Ahmad M, Mehmood A, Farzana K. Rheological studies and characterization of different oils. Journal of the Chemical Society of Pakistan. 2009; 31(2), 201-206.

10. Lee SK, Anema S, Klostermeyer H. The influence of moisture content on the rheological properties of processed cheese spreads. International Journal of Food Science \& Technology. 2004; 39(7), 763-771.

11. Alpaslan M, Hayta M. Rheological and sensory properties of pekmez (grape molasses)/tahin (sesame paste) blends. Journal of Food Engineering. 2002; 54(1), 89-93.

12. ASTM D 341-77, standard viscosity-temperature charts for liquid petroleum products. https:// standards.globalspec.com/std/42202/astm-d341. Date accessed: 1987.

13. Stanciu I. Rheology behavior of soybean oil. Journal of Science and Arts. 2018; 2(43), 453-458. 
14. Stanciu I. Determination viscosity index improvers for multi-grade oil of copolymer polyethylene-propylene Journal of Science and Arts. 2018; 1(42), 197-202.

15. Stanciu I. Viscosity index improvers for multi-grade oil of copolymers polyethylene-propylene and hydrogenated poly (isoprene-co-styrene). Journal of Science and Arts. 2017; 4(41), 771-778. 